\title{
CONTRIBUTO DA ISO 19650-1 PARA A ORGANIZAÇÃO E DIGITALIZAÇÃO DA INFORMAÇÃO UTILIZANDO A METODOLOGIA BIM
}

\author{
Paula Couto $^{(1)}$, Maria João Falcão Silva ${ }^{(1)}$, Filipa Salvado ${ }^{(1)}$, Álvaro Vale e Azevedo ${ }^{(1)}$ \\ (1) Laboratório Nacional de Engenharia Civil (LNEC), Lisboa
}

\begin{abstract}
Resumo
O trabalho colaborativo requer compreensão e confiança mútuas e um nível mais profundo de processos normalizados, do que tem vindo a ser prática corrente no setor da Arquitetura, Engenharia, Construção e Operação (AECO), para que a informação seja produzida e disponibilizada de forma consistente e em tempo útil. Os requisitos de informação são garantia que a informação passada entre os diversos intervenientes ao longo do ciclo de vida de um ativo construído é coerente, representando de forma eficiente o pretendido.

Atualmente são gastos recursos muito consideráveis nas seguintes ações: i) correção de informação não estruturada; ii) gestão incorreta da informação por parte de profissionais, muitas vezes não especializados; iii) resolução de problemas decorrentes de esforços descoordenados das várias equipas envolvidas ao longo do ciclo de vida dos ativos construídos; e iv) resolução de problemas relacionados com reutilização e reprodução de informação.

A norma ISO 19650 vem estabelecer regras para a gestão da informação ao longo de todo o ciclo de vida de um ativo construído, usando os mesmos princípios e requisitos de alto nível da metodologia BIM (Building Information Modelling).

O presente artigo pretende fazer uma reflexão sobre os conceitos, princípios e requisitos para a organização e digitalização da informação em modelos BIM, de acordo com a norma ISO 19650, e considerando todas as fases do ciclo de vida de qualquer ativo construído (conceção, estudo prévio, anteprojeto, projeto de execução, construção, operação, manutenção, reabilitação, fim de vida), com vista a melhorar a gestão dessa informação.
\end{abstract}

\section{Introdução}

O setor da Arquitetura, Engenharia, Construção e Operação (AECO) tem enfrentado diversos problemas, nos anos mais recentes, destacando-se a fraca produtividade, inovação insuficiente, carência de processos consistentes e rigorosos, fornecedores desconectados e fragmentação empresarial [1]. Estes problemas devem-se, principalmente, à falta de processos normalizados 
e à ausência de acompanhamento das novas tecnologias, nomeadamente as de comunicação e informação [2].

A metodologia BIM e as tecnologias de informação têm vindo a transformar o setor, promovendo a criação de ambientes digitais que fomentam as trocas de informação e potenciam a digitalização dos processos [3]. As alterações observadas obrigam à definição objetiva dos processos e à concretização de modelos digitais para suporte e gestão dessa informação [4]. No entanto, ainda são gastos recursos muito consideráveis na correção de informação não estruturada, na gestão incorreta da informação, na resolução de problemas decorrentes da descoordenação das várias equipas envolvidas ao longo do ciclo de vida dos ativos construídos e na resolução de problemas relacionados com a reutilização e reprodução de informação [5]. Com vista a que se possa tirar proveito da informação criada, gerada e armazenada, torna-se necessário definir de forma adequada os requisitos para a sua utilização.

A norma ISO 19650, com as suas partes 1 e 2, vem estabelecer regras para a gestão da informação ao longo de todo o ciclo de vida de um ativo construído, usando os mesmos princípios e requisitos da metodologia BIM. A parte 1 apresenta os conceitos e princípios para a gestão da informação a um nível de desenvolvimento descrito como BIM de acordo com a série ISO 19650", fornecendo recomendações para a criação de uma estrutura com o objetivo de gerir informação, incluindo troca, gravação, versão e organização para todos os atores, sendo aplicável a todo o ciclo de vida de qualquer ativo construído [6]. A parte 2 especifica requisitos para a gestão da informação, na forma de um processo de gestão, dentro do contexto da fase de entrega de ativos e das trocas de informações neles contidas, usando o BIM. A parte 2 pode ser aplicada a todos os tipos de ativos e a todos os tipos e tamanhos de organizações, independentemente da estratégia de aquisição escolhida [7].

No presente artigo pretende-se fazer uma reflexão sobre a descrição dos conceitos, dos princípios e dos requisitos para a organização e digitalização da informação em modelos BIM, de acordo com a norma ISO 19650, considerando todas as fases do ciclo de vida de qualquer ativo construído com vista a melhorar a gestão dessa informação. Este documento, embora ainda sucinto, pretende apresentar um contributo objetivo para a tradução da referida norma e a sua adaptação para a realidade portuguesa.

\section{Enquadramento}

\subsection{Princípios gerais e enquadramento}

$\mathrm{O}$ conceito BIM ainda possui atualmente diversas interpretações. A título de exemplo refere-se que, para fins de estudo, o National Institute of Building Sciences (NIBS) divide o BIM em três níveis de abordagem podendo ser entendido como [8]: i) Produto: depois de passar pelo processo de criação que teve por base as ferramentas de informação e os processos abertos do projeto, o resultado é um modelo da edificação; ii) Ferramenta: são as aplicações informáticas capazes de interpretar, representar, agregar, transmitir e receber as informações do modelo da edificação; iii) Processo: as diferentes especialidades de um projeto trabalham simultaneamente e em colaboração umas com as outras durante todas as fases do ciclo de vida de uma construção [9].

Do ponto de vista conceptual, o BIM é um método de produção, integração e gestão da informação entre todos os intervenientes de um projeto e é transversal a todas as fases do ciclo de vida de uma construção [10]. O BIM permite que exista uma troca de informação mais 
simples e ao mesmo tempo mais detalhada entre todos os intervenientes de um projeto, desde o engenheiro ao dono de obra, possibilitando que todos os envolvidos no processo de construção visualizem o modelo de diferentes perspetivas, permitindo modificar ou acrescentar informações em tempo real, consoante a sua especialização [11].

O BIM tem por base um modelo digital manipulável que permite simular virtualmente, através de um software adequado às necessidades, o ambiente real [12] e possibilita trabalhar com objetos específicos, adaptando-os ao espaço e ao meio envolvente, através da modelação e das relações paramétricas [5]. A modelação por objetos consiste na realização de um modelo virtual através da escolha e montagem de objetos pré-definido numa biblioteca disponibilizada pelo software. Qualquer alteração num dos parâmetros dos objetos faz com que ao longo de todo o modelo haja uma atualização constante e em tempo real da informação modificada, garantindo que o modelo esteja sempre atualizado, independentemente das escolhas do utilizador [13-14].

\subsection{Normas ISO 19650}

A série de normas ISO 19650 foi preparada pelo Comitê Técnico ISO / TC 59 "Buildings and civil engineering works" em colaboração com o Comitê Técnico CEN / TC 442 "Building Information Modelling (BIM)". Esta série de normas pode beneficiar de um processo formal de gestão de ativos como, por exemplo, na série de normas ISO 55000. A série de normas ISO 19650 também pode beneficiar de uma abordagem sistemática da gestão da qualidade dentro de uma organização como, por exemplo, verificado na ISO 9001, muito embora a certificação, no caso da ISO 9001, não seja um requisito da série ISO 19650.

A norma ISO 19650-1 estabelece os conceitos e princípios recomendados para processos em todo o ambiente construído, surgindo como suporte à gestão e produção da informação durante o ciclo de vida dos ativos construídos ao usar o BIM. Esses processos podem fornecer resultados comerciais benéficos aos proprietários / gestores de ativos, clientes e aos envolvidos no financiamento do projeto, incluindo aumento de oportunidades, redução de riscos e redução de custos através da produção e uso de modelos de informação sobre projetos e ativos. Neste documento, a forma verbal "deveria" é usada para indicar uma recomendação. Este documento destina-se principalmente a: i) pessoas envolvidas na aquisição, projeto, construção e / ou gestão de ativos construídos; e ii) pessoas envolvidas em atividades de gestão de ativos, incluindo operação e manutenção. A norma ISO 19650 é aplicável a ativos construídos e projetos de construção de todos os tamanhos e níveis de complexidade. Isso inclui grandes propriedades, redes de infraestruturas, edifícios individuais e partes de infraestruturas e os projetos ou conjuntos de projetos que os desenvolvem. No entanto, os conceitos e princípios incluídos na ISO 19650-1 devem ser aplicados de maneira proporcional e apropriada à escala e complexidade de cada ativo e / ou projeto. Também é importante que a aquisição e a mobilização de partes designadas por ativos ou projetos sejam integradas, tanto quanto possível, aos processos existentes para aquisição e mobilização técnica [6].

A norma ISO 19650-2 pode ser usada por qualquer parte requerente (dono de obra, gestor de ativo, cliente, etc.). Se a parte requerente pretender que este documento se aplique a qualquer ativo (projeto), isso deve refletir-se no compromisso. Este documento define o processo de gestão da informação, contendo as atividades através das quais as equipas envolvidas podem produzir informação de forma colaborativa, minimizando e evitando atividades desnecessárias. A ISO 19650-2 destina-se principalmente a ser utilizada pelos: i) envolvidos na gestão ou produção de informações durante o período de desenvolvimento de ativos; ii) envolvidos na definição e aquisição de projetos de construção; iii) envolvidos na especificação de 
compromissos e facilitação do trabalho colaborativo; iv) envolvidos no projeto, construção, operação, manutenção e desativação de ativos; e v) pelos responsáveis pela realização de valor para as organizações, a partir da sua base de ativos. Este documento contém os requisitos associados à gestão da informação durante o período de desenvolvimento dos ativos construídos, que necessitarão de ser revistos com regularidade até que as melhores práticas sejam estabelecidas e efetuadas [7].

\subsection{BIM na ISO 19650}

A gestão da informação é distinta da respetiva produção e entrega, mas estão intimamente ligadas. A gestão de informação deve ser efetuada durante todo o ciclo de vida do ativo. As funções de gestão de informação deverão ser atribuídas às entidades adequadas (entidade requerente, entidade fornecedora e entidades fornecedoras líder) e não deverão necessariamente conduzir ao envolvimento de novas entidades. A quantidade de informação a gerir aumenta progressivamente, quer durante a fase de desenvolvimento, quer durante a fase operacional. No entanto, apenas a informação relevante deverá ser tornada disponível ou transferida entre as atividades da fase operacional e da fase de desenvolvimento (e vice-versa).

Um processo de gestão da informação é iniciado sempre que é feito um novo compromisso de fase de desenvolvimento ou de fase operacional, independentemente desse compromisso ser formal ou informal. Este processo envolve a preparação de requisitos de informação, a análise das possíveis entidades fornecedoras em relação à gestão da informação, o planeamento inicial / detalhado de como e quando será entregue a informação e a análise dos entregáveis de informação em relação aos requisitos de informação, antes de serem integrados nos sistemas operacionais. O processo de gestão da informação deve ser aplicado de maneira proporcional à escala e complexidade das atividades de gestão de projetos ou ativos.

Os requisitos de informação são distribuídos de forma encadeada à entidade fornecedora mais relevante no contexto da equipa de desenvolvimento. Os entregáveis de informação são recolhidos, pela entidade fornecedora líder, previamente à entrega à entidade requerente, através de troca de informação. A troca de informação é também utilizada para transferência de informação entre as entidades fornecedoras líder, sempre que tal seja autorizado pela entidade requerente. $\mathrm{O}$ fluxo de trabalho do Ambiente Comum de Dados (CDE) é utilizado como suporte aos processos colaborativos de produção, gestão, partilha e troca de toda a informação durante as fases operacional e de desenvolvimento. Os modelos de informação que contêm entregáveis de informação federados são produzidos como resultado do fluxo de trabalho CDE para responder às perspetivas de todas as partes interessadas.

No contexto do processo de gestão da informação, o número e a descrição das subdivisões do ciclo de vida do ativo (retângulos sólidos), pontos de troca de informação (círculos sólidos) e pontos de decisão para equipas de desenvolvimento, partes interessadas ou entidade requerente (diamantes) devem refletir a prática local, requisitos da parte interessada e da entidade ordenante, e quaisquer acordos ou requisitos específicos para a entrega de projeto ou gestão de ativos.

\section{Organização e digitalização da informação em modelos BIM: ISO 19650-1}

Os conceitos e princípios básicos contidos na ISO 19650-1 são direcionados a todos os envolvidos no ciclo de vida do ativo. Isso inclui, entre outros, o proprietário / operador do ativo, 
o cliente, o gestor do ativo, a equipa de projeto, a equipa de construção (empreiteiro), fabricantes de equipamentos, especialistas técnicos, autoridades reguladoras, investidores, seguradoras e utilizadores finais.

\subsection{Conceitos básicos}

Em relação aos conceitos básicos estão incluídos: i) termos gerais; ii) termos relacionados com ativos e projetos; e iii) termos relacionados com a gestão da informação. Para os termos gerais são considerados os seguintes: i) matriz de responsabilidades; e ii) espaço. Quanto aos termos relacionados com ativos e projetos, estão incluídos os seguintes: i) ator; ii) compromisso; iii) entidade fornecedora; iv) entidade requerente; v) cliente; vi) equipa de desenvolvimento; vii) equipa de trabalho; viii) ativo; ix) informação de projeto; $x$ ) ciclo de vida; xi) período de desenvolvimento; xii) período operacional; xiii) evento desencadeador; e xiv) momento chave de decisão. Por fim, são considerados os termos relacionados com a gestão da informação: i) informação; ii) requisitos de informação; iii) requisitos de informação organizacionais (OIR); iv) requisitos de informação do ativo (AIR); v) requisitos de informação do projeto (PIR); vi) requisitos de troca de informação (EIR); vii) troca de informação; viii) modelo de informação; ix) modelo de informação do ativo (AIM); x) modelo de informação do projeto (PIM); xi) federação; xii) bloco de informação; xiii) código de estado; xiv) modelação de informação na construção; xv) ambiente comum de dados (CDE); xvi) nível de informação necessário; xvii) competência; e xviii) capacidade [6].

\subsection{Requisitos fundamentais}

\subsubsection{Princípios}

A entidade requerente deve entender que informação sobre os seu(s) ativo(s) ou projeto(s) é necessária para apoiar os seus objetivos organizacionais ou de projeto. Estes requisitos podem vir da sua própria organização ou de entidades externas interessadas. A entidade requerente deve poder expressar esses requisitos a outras organizações e indivíduos que têm que conhecêlos, quer para especificar, quer para informar, o seu trabalho. Isto aplica-se a ativos e projetos de todas as dimensões, mas os princípios neste documento devem ser aplicados proporcionalmente. As entidades requerentes menos experientes podem procurar assistência especializada para ajudar nestas tarefas. As entidades fornecedoras, incluindo o líder das entidades fornecedoras, podem acrescentar os seus próprios requisitos de informação àqueles que recebem. Alguns dos requisitos de informação podem ser transferidos para as suas próprias entidades fornecedoras, principalmente quando a troca de informação dentro de uma equipa de desenvolvimento é necessária e esta informação não é para ser trocada com a entidade requerente.

A entidade requerente deve declarar os seus propósitos para exigir entregáveis de informação, incluindo os aspetos do ativo que devem ser geridos. Estes propósitos podem incluir:

i) registo de ativos: deve ser fornecido um registo de ativos para apoiar auditorias e relatórios precisos; isto deve incluir ativos espaciais e físicos e os seus agrupamentos;

ii) suporte às responsabilidades regulamentares e de conformidade: a entidade requerente deve especificar as informações necessárias para apoiar a manutenção da saúde e segurança dos utilizadores do ativo; 
iii) gestão de riscos: as informações devem ser exigidas ou suprimidas para apoiar a gestão de riscos, especialmente para identificar e rever os riscos aos quais um projeto ou ativo pode ser exposto, por exemplo, riscos naturais, eventos climáticos extremos ou incêndio; ou

iv) suporte para questões comerciais: a entidade requerente deve especificar a informação necessária para apoiar a análise do negócio em questão quanto à propriedade e operação do ativo; isto deve incluir o desenvolvimento contínuo dos impactos subsequentes e aspetos benéficos do ativo, desde o primeiro entregável:

v) gestão da capacidade e da utilização: deve ser fornecida documentação da capacidade e da utilização pretendidas do ativo pois é necessário para apoiar comparações do uso e da utilização reais e gestão de portfólio;

vi) gestão de segurança e vigilância: a informação deve ser exigida ou suprimida para apoiar a gestão da segurança e vigilância do ativo e dos locais vizinhos ou adjacentes, de acordo com os requisitos de segurança;

vii) apoio à renovação: a renovação de cada espaço ou local e de todo o ativo deve ser apoiada com informação detalhada sobre a capacidade, em termos de áreas, espaços, ocupação, condições ambientais e carga estrutural;

viii)impactos previstos e reais: a entidade requerente deve exigir informação sobre os impactos em qualidade, custo, programação, carbono (CO2e), energia, resíduos, consumo de água ou outros efeitos ambientais;

ix) operações: deve ser fornecida a informação necessária para as operações normais do ativo por forma a ajudar a entidade requerente a antecipar o custo da operação do ativo;

x) manutenção e reparação: deve ser fornecida informação sobre as tarefas de manutenção recomendadas, incluindo manutenção preventiva planeada, para ajudar a entidade requerente a antecipar e planear os custos de manutenção;

xi) substituição: deve estar disponível para a entidade requerente a informação sobre a vida útil e os custos de referência ou de reposição esperados para antecipar os custos de substituição; a reciclagem dos ativos físicos deve ser apoiada com informação detalhada relacionada com os principais materiais constituintes; e

xii) descomissionamento e descarte: deve ser fornecida informação sobre o descomissionamento recomendado para ajudar a entidade requerente a antecipar e planear os custos de fim de vida.

Os requisitos de informação associados à fase de entrega de um ativo devem ser expressos em termos das etapas do projeto que a entidade requerente ou a líder das entidades fornecedoras pretende usar. Os requisitos de informação associados à fase operacional de um ativo devem ser expressos em termos de eventos despoletadores previsíveis no ciclo de vida, como manutenção planeada ou reativa, inspeção de equipamento de incêndio, substituição de componentes ou mudança de fornecedor de gestão de ativos. Os diferentes tipos de requisitos e modelos de informações são mostrados na Figura 1 e explicados nos pontos 3.2.2 a 3.2.7. 


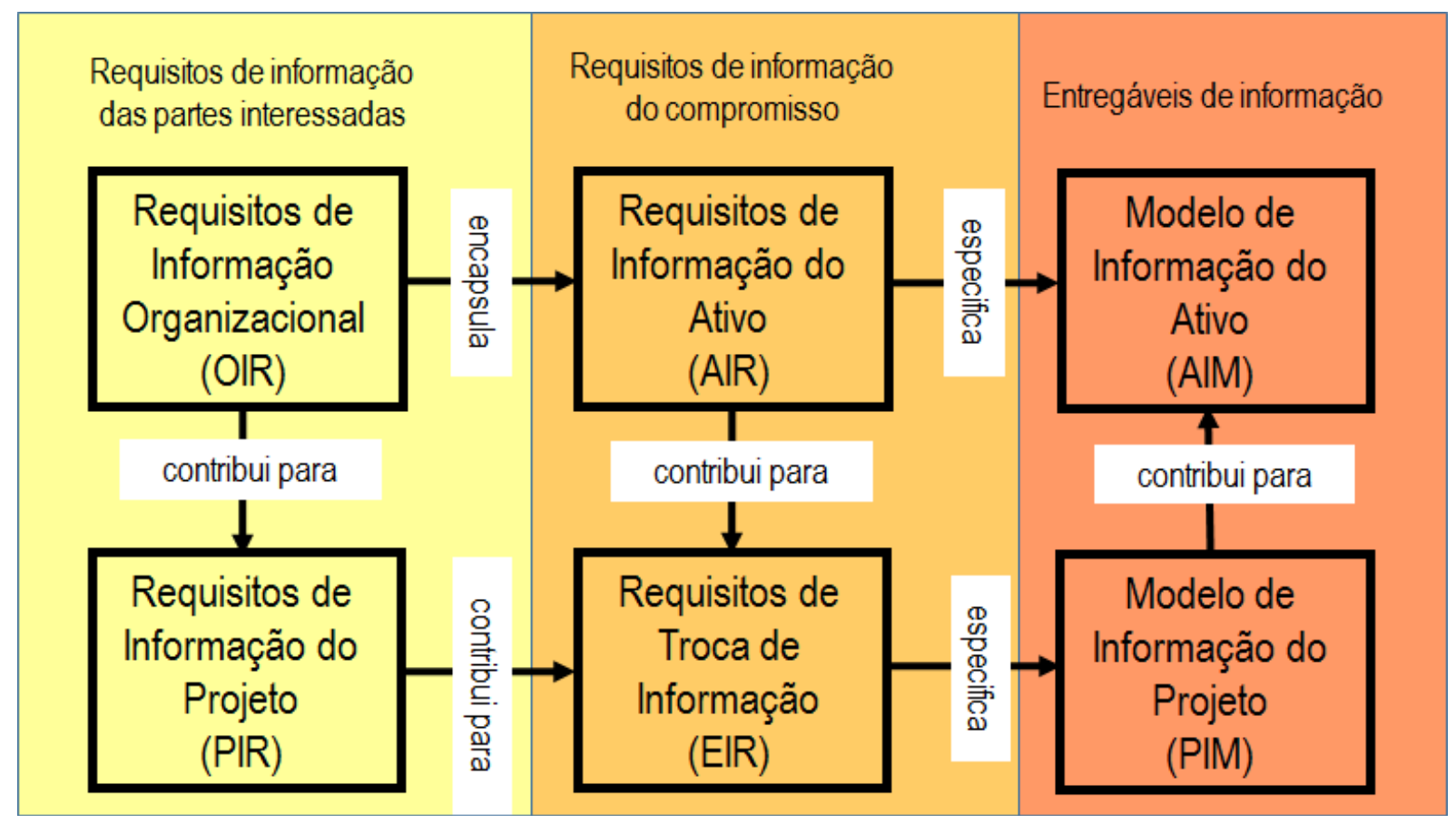

Figura 1: Hierarquia de requisitos de informação, adaptado de (ISO 19650-1; 2018).

\subsubsection{Requisitos de Informação Organizacional (OIR)}

O OIR explica a informação necessária para responder ou informar os objetivos estratégicos de alto nível dentro da entidade requerente. Esses requisitos podem surgir por vários motivos, incluindo: i) operação estratégica de negócios; ii) gestão estratégica de ativos; iii) planeamento de portfólio; iv) deveres regulamentares; ou v) elaboração de políticas. O OIR pode existir por outros motivos que não a gestão de ativos, por exemplo, em relação ao envio de relatórios financeiros anuais. Estes OIR não são abordados neste documento.

\subsubsection{Requisitos de Informação do Ativo (AIR)}

O AIR estabelece aspetos de gestão, comerciais e técnicos da produção de informação sobre ativos. Os aspetos de gestão e comerciais devem incluir o padrão de informação e os métodos e procedimentos de produção a serem implementados pela equipa de desenvolvimento. Os aspetos técnicos do AIR especificam essa informação detalhada necessária para responder ao OIR relacionado com o ativo. Estes requisitos devem ser expressos de forma a que possam ser incorporados nos compromissos de gestão de ativos para apoiar a tomada de decisão organizacional. Deve ser preparado um conjunto de AIR em resposta a cada evento despoletador durante a operação do ativo e, quando apropriado, também deve referir -se aos requisitos de segurança. Quando houver uma cadeia de fornecimentos, o AIR recebido por uma líder das entidades fornecedoras pode ser subdividido e passado em qualquer um de seus próprios compromissos. O AIR recebido pela entidade fornecedora líder pode ser aumentado com os seus próprios requisitos de informação. Numa estratégia e plano de gestão de ativos, podem existir vários compromissos diferentes. O AIR de todos eles deve formar um único conjunto coerente e coordenado de requisitos de informação, suficiente para atender a todos os OIR relacionados com ativos. 


\subsubsection{Requisitos de Informação do Projeto (PIR)}

O PIR explica a informação necessária para responder ou informar os objetivos estratégicos de alto nível da entidade requerente em relação a um projeto específico de ativo construído. Os PIR são identificados no processo de gestão de projetos e no processo de gestão de ativos. Deve ser preparado um conjunto de requisitos de informação para cada um dos principais pontos de decisão da entidade requerente durante o projeto. Clientes recorrentes podem desenvolver um conjunto genérico de PIR que pode ser adotado, com ou sem alteração, em todos os seus projetos.

\subsubsection{Requisitos de Troca de Informação (EIR)}

O EIR estabelece aspetos de gestão, comerciais e técnicos da produção de informação do projeto. Os aspetos de gestão e comerciais devem incluir o padrão de informação e os métodos e procedimentos de produção a serem implementados pela equipa de desenvolvimento. Os aspetos técnicos do EIR devem especificar a informação detalhada necessária para responder ao PIR. Estes requisitos devem ser expressos de forma a que possam ser incorporados nos compromissos relacionados com o projeto. O EIR normalmente deve estar alinhado com os eventos despoletadores que representam a conclusão de algumas ou de todas as fases do projeto. O EIR deve ser identificado sempre que os compromissos estiverem a ser estabelecidos. Em particular, o EIR recebido pela entidade fornecedora líder pode ser subdividido e passado para qualquer uma das suas entidades fornecedoras, e assim por diante ao longo da cadeia de fornecimentos. $\mathrm{O}$ EIR recebido pelas entidades fornecedoras, incluindo as entidades fornecedoras líder, pode ser aumentado com o seu próprio EIR. Alguns EIR podem ser passados para as próprias entidades fornecedoras, principalmente quando a troca de informação dentro de uma equipa de desenvolvimento é necessária e essa informação não deve ser trocada com a entidade requerente. Num projeto, podem existir vários compromissos diferentes. O EIR de todos esses compromissos deve formar um único conjunto coerente e coordenado de requisitos de informação, suficiente para atender a todos os PIR.

\subsubsection{Modelo de Informação do Ativo (AIM)}

O AIM apoia os processos estratégicos e diários de gestão de ativos estabelecidos pela entidade requerente. Também pode fornecer informação no início do processo de desenvolvimento do projeto. Por exemplo, o AIM pode conter registos de equipamento, custos cumulativos de manutenção, registos de datas de instalação e manutenção, detalhes de propriedade e outros detalhes que a entidade requerente considere de valor e deseje gerir de forma sistemática.

\subsubsection{Modelo de Informação do Projeto (PIM)}

O PIM suporta a entrega do projeto e contribui para o AIM para apoiar as atividades de gestão de ativos. O PIM também deve ser armazenado para fornecer um arquivo de longo prazo do projeto e para fins de auditoria. Por exemplo, o PIM pode conter detalhes da geometria do projeto, localização do equipamento, requisitos de desempenho durante a atividade do projetista, método de construção, planeamento, orçamentação e detalhes dos sistemas de instalações, componentes e equipamento, incluindo requisitos de manutenção, durante a construção do projeto. 


\section{Considerações Finais}

Os projetos portugueses apresentam, cada vez mais, diferentes graus de complexidades e de especificidade, não só pela cultura empresarial característica do país, como também pelos fatores económicos e geográficos que lhes estão associados. É cada vez mais importante o seu acompanhamento, desde as fases primordiais, por forma a apurar as necessidades e exigências de informação associadas concretamente a cada empreendimento.

Os conceitos e os princípios mencionados na ISO 19650-1 alteram a forma de pensar na informação criada em projeto e a forma como é gerida em operação. A digitalização é inevitável, e cada vez mais se irá trabalhar sobre informação em suporte digital, pelo que o setor AECO não será um caso diferente dos demais. De facto, os conceitos e princípios referidos, afiguram-se como um pequeno passo no sentido desta nova era da digitalização, sendo que a sua aplicação permite uma boa gestão da informação digitalizada, valorizando as diferentes fases do ciclo de vida dos ativos construídos, com particular enfoque na fase de exploração e operação.

A definição de requisitos de informação, conforme estabelecido na ISO 19650-1, é essencial para a criação de modelos úteis e eficazes. Os requisitos traduzem uma "linguagem comum" entre a entidade detentora do empreendimento e os fornecedores de informação, existindo para que seja exija apenas a informação necessária em cada fase, e não toda a informação possível. O nível de informação necessário deve, pois, ser transmitido sobre a forma de requisitos. As necessidades de informação de cada entidade deverão ser bem conhecidas, pois os requisitos têm de ser exequíveis pelos fornecedores de informação, não podendo ser inatingíveis ou irrealistas.

\section{Referências}

[1] WEF (2016). Shaping the Future of Construction - A Breakthrough in Mindset and Technology. World Economic Forum.

[2] Campos, L (2017). Conceitos para a Utilização de Informação Digitalizada no Ciclo de Vida de Empreendimentos de Construção. Dissertação de Mestrado, IST-UL.

[3] Eastman, C. et al. (2011). BIM Handbook - A Guide to Building Information Modeling for Owners, Managers, Designers, Engineers, and Contractors. Segunda edição. Hoboken, New Jersey: John Wiley \& Sons, Inc. isbn: 9780470541371.

[4] Azhar, S. (2011). Building Information Modeling (BIM): Trends, Benefits, Risks, and Challenges for the AEC Industry. Leadership and Management in Engineering 11, pp. 241-252.

[5] Nascimento, L.; Santos, E. (2002). Barreiras para o uso da tecnologia da informação na indústria da construção civil.

[6] ISO 19650-1:2018, Organization and digitalization of information about buildings and civil engineering works, including building information modelling (BIM) - Information management using building information modelling - Part 1: Concepts and principles, CENEuropean Commission for Standardization, Bruxelas, 1st edition.

[7] ISO 19650-2:2018. Organization and digitalization of information about buildings and civil engineering works, including building information modelling (BIM) - Information 
management using building information modelling - Part 2: Delivery phase of assets, CEN- European Commission for Standardization, Bruxelas, 1st edition.

[8] National Institute of Building Sciences (2007). National Building Information Modeling Standard. V.1 - Part1: Overview, principles and methodologies. Whashington, 1-183 pp.

[9] Giollo, R. (2016). Dissertação de mestrado, Universidade Lusófona de Humanidades e Tecnologias.

[10]Falcão Silva, M. J., Salvado, F., Couto, P., Vale e Azevedo, A. (2015). Sistematização da informação técnica e económica da construção para incorporação em objetos BIM, COMPAT 2015, Lisboa, Portugal.

[11] Gonçalves, I. (2014). Aplicação do BIM ao projeto de estruturas. Tese de Mestrado. Instituto Politécnico de Viana do Castelo.

[12] 3. ${ }^{\circ}$ Fórum PTPC (2014). Plataforma Tecnológica Portuguesa da Construção. "O BIM no futuro da Construção", em 3. Fórum PTPC (2014), Lisboa, Portugal.

[13]Lopes, J. (2017). Interoperabilidade entre objetos BIM e a aplicação ProNIC na especialidade de Instalações Prediais. Tese de Mestrado. Faculdade de Engenharia da Universidade Nova de Lisboa.

[14] Underwood, J., Isikdag, U. (2010). Handbook of Research on Building Information Modeling and Construction Informatics: Concepts and Technologies. Primeira edição. Hershey, Pennsylvania: Information Science Reference. ISBN: 9781605669298. 